\title{
The "Quarantine Dry Eye": The Lockdown for Coronavirus Disease 2019 and Its Implications for Ocular Surface Health
}

This article was published in the following Dove Press journal: Risk Management and Healthcare Policy

\author{
Pietro Emanuele Napoli $\mathbb{D}^{1, *}$ \\ Matteo Nioi iD ${ }^{2}$ \\ Maurizio Fossarello ${ }^{1,3, *}$ \\ 'Department of Surgical Science, \\ University of Cagliari, Eye Clinic, Cagliari, \\ Italy; ${ }^{2}$ Department of Clinical Sciences \\ and Public Health, University of Cagliari, \\ Forensic Medicine Unit, Cagliari, Italy; \\ ${ }^{3}$ Clinica Oculistica, San Giovanni di Dio \\ Hospital, Azienda Ospedaliera \\ Universitaria di Cagliari, Cagliari, Italy \\ *These authors contributed equally to \\ this work.
}

Correspondence: Pietro Emanuele Napoli Email pietronapoli@ymail.com

\begin{abstract}
The pandemic of coronavirus disease 2019 (COVID-19) has led many countries of the world to impose a series of containment measures such as lockdowns (mass quarantines), curfews or similar restrictions (eg, stay-at-home orders, or shelter-in-place orders). All these restrictions were established in order to limit spread of COVID-19. Thus, approximately 3.9 billion people worldwide were under lockdown by early April 2020. During this time (home confinement), some solutions have been proposed by experts to improve work and school productivity, including smart working and online school lessons. However, many of the restrictive measures are likely to act as predisposing factors for dry eye disease (DED), directly or related to sick building syndrome (SBS). Herein, we discuss the implications of quarantine measures on eye health, in particular on DED associated with SBS, and introduce some potential preventive strategies for lockdown-related ocular surface disorders. Several risk factors are implicated in their pathogenesis, including environmental changes (eg, air quality) and modifications in personal behaviors (eg, the abuse of digital devices, malnutrition, and sleep/psychiatric disorders). Considering a number of predisposing factors for $\mathrm{DED}$, it is possible to state that patients under lockdown are at risk of ocular surface alterations. Accordingly, the COVID-19 pandemic era is expected to determine an increase in dry eye patients all around the world (a new phenomenon that we propose to name the "quarantine dry eye") in the event that the restrictive measures will be recursively extended over time.
\end{abstract}

Keywords: COVID-19, dry eye diseases, sick building syndrome, ocular surface, coronavirus, SARS-CoV-2, tear film, lockdown, quarantine, display device

\section{Introduction}

Since first being recorded late last year in China, the novel coronavirus disease 2019 (COVID-19) has spread around the world in a matter of months, touching every continent save Antarctica. Efforts to stem the spread of the ongoing pandemic have prompted most Governments to impose to billions of people around the world a series of containment measures to prevent physical contact, such as lockdowns (mass quarantines), curfews or similar restrictions (eg, stay-at-home orders, public gathering bans, or shelter-in-place orders). In most countries, temporary closure of schools, universities and colleges, offices and industries, have been applied.

Notably, India, France, Italy, New Zealand, Poland, Israel, Spain and the United Kingdom are the countries that have implemented the world's largest and most restrictive mass quarantines. For example, in Northern Italy approximately 50,000 
people were closed in a cordon sanitaire on 22 February 2020, and in India more than 1.3 billion of people were under lockdown by late April of the same year. ${ }^{1}$ Overall, more than half of the world's population has been under lockdown by early April 2020. ${ }^{2-4}$ Similar restrictions are foreseen in the USA and in Brazil.

Herein, we discuss the risk factors associated with quarantine measures of home confinement on eye surface health, with particular emphasis on those situations likely to trigger dry eye syndrome and sick building syndrome (as defined below). Moreover, we introduce a number of potential preventive strategies for lockdown-related ocular surface disorders.

\section{Risk Factors for Dry Eye Disease During the Pandemic of COVID-I 9}

During quarantine, some models of work/school at home have been proposed to improve productivity, including smart working and online school lessons, essentially based on use of video display terminals (VDTs). Undoubtedly, these models of smart working with VDTs have produced new styles of life, the digital work and the digital school, constraining people, young and adults, to prolonged near visual work. Unfortunately, the prolonged use of VDTs may predispose to ocular surface disorders, such as dry eye disease (DED), which are associated with local and visual symptoms (eg, eye strain).

Although DED is among the most common eye diseases around the world, its impact on the overall health of patients is often underestimated. Dry eye represents essentially a change in the precorneal tear film regularity and dynamic. Any local change of tear film may cause both vision-related and ocular surface-related symptoms. In particular, vision deterioration and the changes of optical quality in patients with DED imply decreased quality of life. ${ }^{5}$ DED has recently been defined by the TFOS DEWS II as

a multifactorial disease of the ocular surface characterized by a loss of homeostasis of the tear film, and accompanied by ocular symptoms, in which tear film instability and hyperosmolarity, ocular surface inflammation and damage, and neurosensory abnormalities play etiological roles. ${ }^{5}$

\section{Environmental Factors and Personal Behaviors}

The continuous need to redefine the disease over the last twenty years only partly explains its great pathogenetic and diagnostic complexity. ${ }^{6-11}$ In fact, several risk factors are implicated in the pathogenesis of DED, including environmental factors (eg, air quality), and personal behaviors such as the abuse of digital devices (DDs) in general, eg, mobile phone, TV, or video display terminals (VDTs). ${ }^{12,13}$ In these cases, DED may occur as a consequence of reduced rate of blinks (eg, due to the increased exposure to short-wavelength blue light), or of poor quality of blinking (often incomplete). Interestingly, the prevalence of dry eye among visual display workers was found to be particularly high in young adults from large cross-sectional studies. ${ }^{14,15}$ The widespread use of DDs such as home computers, tablets and electronic devices, has significantly contributed to the spread of this eye disorder in the general population, even in young children aged 0-4 years. ${ }^{16}$ Accordingly, pediatric DED has been strongly associated with smartphone use in children in urban environments, while outdoor activity appeared to play a protective role. ${ }^{13,17}$

Moreover, a sedentary behavior due to a general reduction of physical activity may also predispose to DED.

In other cases, the combination of multiple risk factors, for example, air-conditioned environments and performing work at VDTs, has led the experts to coin the term "office eye syndrome". ${ }^{18,19}$ Tear evaporation, for example, rises in conditions of increased airflow over the surface of the eye (eg, a fan or, in general, air conditioning) and low humidity. ${ }^{20}$ For instance, 90 minutes spent in an environment with low humidity are sufficient to induce ocular discomfort and the appearance of pro-inflammatory agents in tears. ${ }^{20}$

Eye irritation and DED have also been observed in people occupying a building for a prolonged length of time, a situation in which the occupants experience discomfort or acute health effects that seem related directly to the time spent in the building. This condition, classified as Sick building syndrome (SBS) ${ }^{21}$ has not been associated with specific illness or cause. ${ }^{22}$ Generally, symptoms start within a few hours, and improve within minutes of leaving the building. Since SBS often worsens in winter, it is very likely associated with low sunlight exposure. There appeared also some association between SBS symptoms and poor air quality (eg, particulates in the air), low fresh air ventilation rates, high temperature, low humidity, presence of dust, and the elevated microbial content of the air. $^{23}$

Symptoms of DED related to SBE can be more pronounced in people wearing contact lenses, who may find 
difficult to wear them throughout the day. ${ }^{24}$ The objective signs include a reduced stability of the tear film, decreased foam in the internal epicanthus, and damages of ocular surface epithelia. Overall, the DED associated with SBS can induce a reduced quality of life and a decreased productivity of the workers.

\section{Dietary Implications on the Ocular Surface During COVID-19 Lockdown}

A further issue related to DED may be represented by changes of eating and drinking habits secondary to the lockdown. The closing of restaurants, pubs, bars and cafeterias, as well as the increased time spent at home have induced more individuals and families to spend more time preparing and eating food at home (eg, cakes, pizzas, or bread). Breakfast, lunch, dinner, and snacks preparation and consuming have become a relevant home activity for many persons. Moreover, the shortage of some fresh ingredients may have changed eating habits and favored stockpiling. In particular, a larger portion and wider variety of foods available during the lockdown are likely to be frozen. However, it is essential to adopt a varied and balanced diet to ensure a quantitative and qualitative healthy supply of all nutrients required for the proper functioning of the eyes. The role of certain nutrients in the prevention and management of DED has been the subject of numerous studies and the interest of the pharmaceutical industry. ${ }^{25}$ The main nutritional deficiency which has been associated to DED is the lack of vitamin A and D, and of essential fatty acids. ${ }^{26-32}$ Subjects suffering from, or at risk of dry eye, must pay attention to maintain adequate levels of these two vitamins in their diet.

It is essential to note that since lockdown is related with disruption of the work routine, this could lead to boredom. ${ }^{33}$ The latter has in turn been associated with higher energy intake, as well as the consumption of more carbohydrates, fats and proteins. ${ }^{34}$ This unhealthy nutritional habit could increase the risk of developing obesity, which is considered to be a chronic state of inflammation paradoxically associated with nutritional deficiencies. ${ }^{35}$ Furthermore, during the quarantine the increase in macronutrient intake could also be accompanied by a deficiency of micronutrients as occurs in obesity. ${ }^{33,36}$ In fact, a diet poor in vegetables and fruit is frequently observed during isolation, resulting in a low intake of vitamins and antioxidants, and in association with reduced physical activity. $^{37}$
Lockdown-related stress also causes sleep disturbances and psychiatric problems that further worsen emotional tension and increase food intake (in particular sugar-rich food) and alcohol drinking, creating a dangerous vicious cycle. ${ }^{33}$ Conversely, in developing countries, dietary problems (eg, vitamin and antioxidant deficiency) may be due to poverty and malnutrition.

Also, whole-body hydration may play a role in DED. Suboptimal whole-body hydration is more frequent in people with dry eye, compared with those classified as non-DED. ${ }^{38}$ Although it is not clear at the moment whether improving whole-body hydration may serve as a therapy to reduce DED symptoms, adequate body hydration, not less than 1.5 liter a day of water intake is highly recommended.

Regarding alcohol consumption during COVID-19, coronavirus pandemic, social isolation, and economic uncertainty, undoubtedly may stimulate alcohol drinking for negative reinforcement, to escape, avoid, or regulate unpleasant emotions, like stress. ${ }^{39}$

The World Health Organization (WHO) has specifically warned about alcohol use during the COVID-19 pandemic. ${ }^{40,41}$ The WHO's regional office for Europe recommended governments restrict access to alcohol. ${ }^{42}$

In the USA alcohol beverages recorded a boom of sales, both online and off-premises, compensating at least in part for the impact of closed bars and restaurants, according to data reported by Nielsen, an international measurement and data analytics company. ${ }^{43}$ Other countries probably have scored a similar trend. Some of this increase is undoubtedly stockpiling but is also known from prior experience and studies that periods of economic and psychological stress like this are characterized by an increase of alcohol consumption. ${ }^{44}$ For the past few decades, researchers have held controversial opinions whether alcohol drinking disturbs tear film and ocular surface. ${ }^{45-47}$ However, recent studies suggest that alcohol consumption may be a significant risk factor for DED. ${ }^{48}$

\section{Issues Related to Vitamin A and D, and Essential Fatty Acids}

Vitamin A, also known as retinol, is only found in animalsourced foods, such as oily fish, liver, cheese and butter. ${ }^{49}$ The recommended dietary allowance (RDA) is 900 micrograms (mcg) for men, $700 \mathrm{mcg}$ for women and 300-600 mcg for children and adolescents. For instance, one slice of beef liver contains $6421 \mathrm{mcg}$, while one tablespoon of butter contains $97 \mathrm{mcg}$ of vitamin A. 
However, human body can produce vitamin A from carotenoids found in plants. ${ }^{50}$ These carotenoids include alpha-carotene and beta-carotene, which are collectively known as provitamin A. For instance, 100 grams of cooked sweet potatoes carry $1043 \mathrm{mcg}$, and one cooked medium carrot carry $852 \mathrm{mcg}$. Unfortunately, $45 \%$ of people carry a genetic mutation that significantly reduces their ability to convert provitamin A into vitamin A. Therefore, a more generous dosage of these foods is suggested. During the COVID-19 era, the excess alcohol consumption related to the lockdown, or dietary problems (eg, iron deficiency or malnutrition), can predispose to vitamin A deficiency. ${ }^{51,52}$

Vitamin D is found almost mainly in animal products, so that vegetarians and vegans are at particularly high risk of not getting enough quantity. Vitamin D is the only nutrient the body skin produces when exposed to sunlight. The average RDA is 800 International Unit (IU) (equivalent to $20 \mathrm{mcg}$ ) of vitamin D per day from foods. During lockdown, however, people are expected to be less exposed to sunlight (especially in developed countries), and if they consume a diet low in good sources of this vitamin, they risk not reaching the RDA. ${ }^{53}$ For instance, 100 grams of wild salmon contain 526 IU of vitamin D, $66 \%$ of the RDA. Also, cod liver oil is an excellent source of vitamin D: one teaspoon contains about $500 \mathrm{IU}$. Cod liver oil likewise is a very good source of vitamin A, with $150 \%$ of RDA in just one teaspoon. Cow's milk is another well-known source of vitamin D. It usually contains about $130 \mathrm{IU}$ per cup, and in many countries, is fortified with vitamin D.

Although there is currently not sufficient evidence to support recommending vitamin $\mathrm{D}$ to reduce the risk of COVID-19, given that many people are spending more time indoors and may not get the vitamin D they need for bone and muscle health, some authors consider that vitamin D-deficient patients, and the population in general, should be advised to take a daily supplement containing 800-1000 UI. ${ }^{54}$

It should be remembered that the respect of RDA is important to avoid potential vitamin A and D toxicity on long term.

Poly-unsaturated Fatty Acids (PUFAs) omega 3 and omega 6 have been the elements of the diet most widely reported to have an impact in DED. ${ }^{28,29,50}$ PUFAs derive from essential fatty acids (EFAs) linoleic acid (LA) ( $\mathrm{n}-6)$ and $\alpha$-linolenic acid (ALA) ( $\mathrm{n}-3)$, and they cannot be synthesized by humans (or other higher animals). For these reasons, PUFAs must be directly obtained from the diet. Most crop seeds and vegetable oils, including canola, soybean, corn, and sunflower oils, are major sources of $n$ -6 FAs in the form of LA with low proportions of $n-3$ FAs (ALA). Contrasting to $n-6$ FAs, the intake of $n-3$ FAs is usually inadequate because of their limited sources. ${ }^{50}$ Green leafy vegetables also contain high proportions of PUFAs in the form of ALA. ${ }^{50}$ Diet based on fish, fish oil, beef, and lamb can also supply eicosapentaenoic acid (EPA), docosapentaenoic acid (DPA), docosahexaenoic acid (DHA), and arachidonic acid (ARA) that can be directly utilized for normal physiological functions in the body. ${ }^{55}$ However, during the COVID-19 related lockdown, it may be more difficult to find the aforementioned types of fresh vegetables, fish or meat, unlike repetitive canned foods.

\section{Sleep and Psychiatric Disorder as Risk Factors for DED}

In addition, sleep deprivation and psychological states, such as depression and anger, not only adversely affects the patient's quality of life, but are also significantly associated with DED. The relationship between dry eye symptoms and psychiatric symptoms has been reported in multiple studies ${ }^{56,57}$ Definitely, the uncertainty linked to the COVID-19 pandemic aroused fear, anxiety, worry, stress, and insomnia.

The prevalence of depression symptoms in the US was more than threefold higher during COVID-19 compared with before the COVID-19 pandemic. ${ }^{58}$

During June $24-30,2020,40.9 \%$ of USA adults reported at least one adverse mental or behavioral health condition, including symptoms of anxiety or depressive disorder associated with COVID-19. Younger adults, racial/ethnic minorities, essential workers, and unpaid adult caregivers reported having experienced disproportionately worse mental health outcomes, increased substance use, and elevated suicidal ideation. ${ }^{59}$

The pandemic is likely to have both long- and shortterm implications for mental health and substance use, particularly for groups likely at risk of new or exacerbated mental health struggles. ${ }^{59}$

Under these circumstances, medications are often prescribed. However, neurological and psychiatric medications, such as antidepressant (amitriptyline, sertraline, and paroxetine), antipsychotic (thioridazine) and Parkinson's medication (trihexyphenidyl), may represent 
an additional risk factor of developing or worsen DED. ${ }^{60,61}$

Beyond daytime stress, anxiety and depression, insomnia has been founded in the general population and in special groups, such as the medical staff and college students, during the COVID-19 outbreak. ${ }^{62-68}$

Insomnia can disrupt the lacrimal system and cause DED, through increased tear osmolarity, decreased tear secretion and shortened tear film breakup time. ${ }^{69,70}$ As a result, patients often complain about eye fatigue, presumably due to photophobia and blurred vision induced by tear film instability.

Of note, the COVID-19 lockdown in some countries was associated with a significant increase in purchasing behavior in pharmacies for psychotropic and neurological drugs. $^{71}$ Noticeably, strict lockdown measures can have a more severe negative psychological impact on psychiatric patients. $^{72}$

\section{"Quarantine Dry Eye" in Developed and Developing Countries}

In this paper, we have highlighted the potential connection between DED and the lockdown-related lifestyle, a condition for which we coined the term "quarantine dry eye". Therefore, it is likely to expect an increase of DED patients around the world, particularly in the event that the restrictive measures will be recursively extended over time.

An additional question that may be relevant to this argument is whether the problems of DED will be distributed mainly in the industrialized countries, where majority of people use VDTs for most part of the day, live in places with suboptimal air conditions, are constrained to sedentary style of life, and consume unhealthy foods and beverages.

Probably, in developing countries, the effects of quarantine on DED could prove to be even more distressing, although for different reasons, and difficult to evaluate: many people still live in poverty, often in small hovels in favelas, where malnutrition, hunger and poor health conditions represent a major problem. Moreover, in many developing countries social life and working activities are prevalently outdoors, so that the excessive UV irradiation can play a contributory role in the development of various ocular disorders, such as pterygium, photokeratitis and corneal degenerative changes, leading to serious dry eye in a large part of the population. In these cases, a worsening of symptoms in an already existing endstage DED may be impossible to evaluate.

Beyond this, in some emerging countries, the rules of quarantine have sorted untoward effects on population. In India, for instance, the lockdown sparked mass migration of people from large cities, both for problems of social isolation and fear of hunger, to return to their villages and take refuge in "tree houses", 73 in a sort of unpredictable and extreme outdoor insulation.

\section{Therapeutic Approaches}

From a therapeutic point of view, several recommendations may be useful for patients at risk of "quarantine dry eye", including some behavioral (eg, timed interruptions during smart working, and recurrent forced blinking), ergonomic (eg, down gaze position, laptop instead of PC, or reduced amplitude of eyelid opening), and environmental (eg, avoid fans or air conditioning) measures. Different therapeutic approaches such as the instillation of artificial tears (which often contain substances with antiviral action $^{74}$ ) or the application of warm compresses can also be considered. Of interest, since excessive exposure to blue light from DDs may result in sleep cycle disruption (and indirectly in dry eye), warmer screen tones towards the evening would be desirable, particularly for young people. $^{75,76}$ Some modern software offers this option, including Microsoft's "Night light" and Apple's "Night Shift" (for older or low-quality digital media, "blue light blocking" glasses might play a protective role ${ }^{77}$ ). Similarly, the screen brightness should be adjusted to match the level of room light, and the contrast increased as much as possible to reduce eye strain. A matte screen filter may also reduce the glare. ${ }^{78}$ Moreover, humidifiers for dry and warm rooms as well as corrective glasses ("computer glasses") for astigmatic, hypermetropic or presbyopic patients can be considered. ${ }^{79}$

Clearly, the same recommendations apply to kids with some additional considerations to limit intensive near work. ${ }^{80}$ It is highly desirable to use a timer (eg, kitchen or smart device timer), to make calls to encourage the youngest users to look away from the screens (eg, with paperclips in a book, or using the "bookmark" function on an e-book), to discourage the use of DDs outside or in brightly lit areas (due to the potential glare), and to encourage blinking and adequate distance from digital media, ie, at least 18 to 24 inches $(\sim 45-60 \mathrm{~cm})$.

As regards the new and presumably temporary "home offices" (related to digital work/school), some reflections 
can be made to improve the quality of the indoor environment. First, natural ventilation is preferable to artificial ventilation. Air-conditioned offices are in fact more exposed to pollutants generated by ventilation systems. Second, the facial rash following the use/abuse of DDs should be carefully monitored because it may indicate the precipitation of charged air particles on the skin. In addition, indoor cigarette smoking and the low quality of work software should be strongly discouraged. Overall, all general rules for preventig SBS should be taken in account to limit the risk of ocular and extra-ocular symptoms (eg, HEPA filters, toxin-absorbing plants, regular inspections to detect mold or toxins, adequate placement of office machinery, etc.).

Noticeably, in the poorest countries, economic and social support given by governments or other agencies is of crucial importance to address fundamental problems such as malnutrition, homelessness, vulnerability and poor living conditions associated with decrepit housing units with incomplete or deteriorated infrastructure (eg, slums in urban and suburban areas), and excessive sun exposure (eg, the free supply of UV-protective sunglasses may be very useful).

\section{Conclusion}

In conclusion, various groups of the general population should be carefully monitored for DED during and after lockdowns (eg, children, young adults, or VDT workers). In this sense, "quarantine dry eye" can reduce the quality of life of people and lead to a drastic reduction in work and school efficiency, while timely treatment may promptly limit all these problems.

\section{Acknowledgment}

The authors would like to acknowledge Luigi Ventura for proofreading the article.

\section{Author Contributions}

All authors made a significant contribution to the work reported, whether that is in the conception, study design, execution, acquisition of data, analysis and interpretation, or in all these areas; took part in drafting, revising or critically reviewing the article; gave final approval of the version to be published; have agreed on the journal to which the article has been submitted; and agree to be accountable for all aspects of the work.

\section{Funding}

This research received no external funding.

\section{Disclosure}

The authors declare no conflict of interest.

\section{References}

1. Nair S For a billion Indians, lockdown has not prevented tragedy. The Guardian; March 29, 2020. Accessed September 21, 2020.

2. Euronews. Coronavirus: half of humanity now on lockdown as 90 countries call for confinement. Euronews; April 3, 2020. Accessed September 21, 2020.

3. Napoli PE, Nioi M. Global spread of coronavirus disease 2019 and malaria: an epidemiological paradox in the early stage of $\mathrm{A}$ pandemic. J Clin Med. 2020;9:1138. doi:10.3390/jcm9041138

4. Napoli PE, Nioi M, d'Aloja E, Fossarello M. The ocular surface and the coronavirus disease 2019: does a dual 'Ocular route' exist? J Clin Med. 2020;9:1269. doi:10.3390/jcm9051269

5. Craig JP, Nichols KK, Akpek EK, et al. TFOS DEWS II definition and classification report. Ocul Surf. 2017;15(3):276-283. doi:10.1016/j.jtos.2017.05.008

6. Napoli PE, Nioi M, Mangoni L, et al. Fourier-domain OCT imaging of the ocular surface and tear film dynamics: a review of the state of the art and an integrative model of the tear behavior during the inter-blink period and visual fixation. J Clin Med. 2020;9(3):668. doi: $10.3390 / \mathrm{jcm} 9030668$

7. Napoli PE, Coronella F, Satta GM, Galantuomo MS, Fossarello M. Evaluation of the adhesive properties of the cornea by means of optical coherence tomography in patients with meibomian gland dysfunction and lacrimal tear deficiency. PLoS One. 2014;9(12): e115762. doi:10.1371/journal.pone.0115762

8. Napoli PE, Satta GM, Coronella F, Fossarello M. Spectral-domain optical coherence tomography study on dynamic changes of human tears after instillation of artificial tears. Invest Ophthalmol Vis Sci. 2014;55(7):4533-4540. doi:10.1167/iovs.14-14666

9. Napoli PE, Coronella F, Satta GM, Fossarello M, Novel A. OCT technique to measure in vivo the corneal adhesiveness for sodium carboxymethylcellulose in humans and its validity in the diagnosis of dry eye. Invest Ophthalmol Vis Sci. 2014;55(5):3179-3185. doi:10.1167/iovs.13-13613

10. Napoli PE, Nioi M, d'Aloja E, Fossarello M. The bull's eye pattern of the tear film in humans during visual fixation on en-face optical coherence tomography. Sci Rep. 2019;9(1):1-9. doi:10.1038/ s41598-018-38260-5

11. Napoli PE, Coronella F, Satta GM, Fossarello M. A novel technique of contrast-enhanced optical coherence tomography imaging in evaluation of clearance of lipids in human tears. PLoS One. 2014;9 (11).

12. Tsubota K, Nakamori K. Dry eyes and video display terminals. NEJM. 1993;328(8):584. doi:10.1056/NEJM199302253280817

13. Moon JH, Kim KW, Moon NJ. Smartphone use is a risk factor for pediatric dry eye disease according to region and age: a case control study. BMC Ophthalmol. 2016;16(1):188. doi:10.1186/s12886-0160364-4

14. Stapleton F, Alves M, Bunya VY, et al. Tfos dews ii epidemiology report. Ocul Surf. 2017;15(3):334-365. doi:10.1016/j. jtos.2017.05.003

15. Kaido M, Kawashima M, Yokoi N, et al. Advanced dry eye screening for visual display terminal workers using functional visual acuity measurement: the Moriguchi study. Br J Ophthalmol. 2015;99 (11):1488e92. doi:10.1136/bjophthalmol-2015-306640 
16. Marshall SJ, Gorely T, Biddle SJ. A descriptive epidemiology of screen-based media use in youth: a review and critique. $J$ Adolesc. 2006;29(3):333e49. doi:10.1016/j.adolescence.2005.08.016

17. Moon JH, Lee MY, Moon NJ. Association between video display terminal use and dry eye disease in school children. $J$ Pediatr Ophthalmol Strabismus. 2014;51(2):87-92. doi:10.3928/01913913-20140128-01

18. Tsubota K. Tear dynamics and dry eye. Prog Retin Eye Res. 1998;17:565e96. doi:10.1016/S1350-9462(98)00004-4

19. Franck C. Eye symptoms and signs in buildings with indoor climate problems ('office eye syndrome'). Acta Ophthalmol. 1986;64 (3):306-311. doi:10.1111/j.1755-3768.1986.tb06925.x

20. Alex A, Edwards A, Hays JD, et al. Factors predicting the ocular surface response to desiccating environmental stress. Invest Ophthalmol Vis Sci. 2013;54:3325e32. doi:10.1167/iovs.12-11322

21. Redlich CA, Sparer J, Cullen MR. Sick-building syndrome. Lancet. 1997;349(9057):1013-1016. doi:10.1016/S0140-6736(96)07220-0

22. Joshi SM. The sick building syndrome. Indian J Occup Environ Med. 2008;12(2):61. doi:10.4103/0019-5278.43262

23. Burge PS, Jones P, Robertson AS. Sick building syndrome; environmental comparisons of sick and healthy buildings. Indoor Air. 1990;90:479-483.

24. Burge PS. Sick building syndrome. Occup Environ Med. 2004;61 (2):185-190. doi:10.1136/oem.2003.008813

25. Jalbert I. Diet, nutraceuticals and the tear film. Exp Eye Res. 2013;117:138-146. doi:10.1016/j.exer.2013.08.016

26. Lawrenson JG, Grzybowski A. Controversies in the use of nutritional supplements in ophthalmology. Curr Pharm Des. 2015;21 (32):4667-4672. doi:10.2174/1381612821666150909095916

27. Sommer A. Vitamin A deficiency and clinical disease: an historical overview. J Nutr. 2008;138(10):1835-1839. doi:10.1093/jn/138.10.1835

28. McCusker MM, Durrani K, Payette MJ, Suchecki J. An eye on nutrition: the role of vitamins, essential fatty acids, and antioxidants in age-related macular degeneration, dry eye syndrome, and cataract. Clin Dermatol. 2016;34(2):276-285. doi:10.1016/j.clindermatol.2015.11.009

29. Alanazi SA, El-Hiti GA, Al-Baloud AA, et al. Effects of short-term oral vitamin A supplementation on the ocular tear film in patients with dry eye. Clin Ophthalmol. 2019;13:599-604. doi:10.2147/ OPTH.S198349

30. Yildirim P, Garip Y, Karci AA, Guler T. Dry eye in vitamin D deficiency: more than an incidental association. Int $J$ Rheum Dis. 2015. doi:10.1111/1756-185X.12727

31. Gatell-Tortajada J. Oral supplementation with a nutraceutical formulation containing omega- 3 fatty acids, vitamins, minerals, and antioxidants in a large series of patients with dry eye symptoms: results of a prospective study. Clin Interv Aging. 2016;11:571-578. doi:10.2147/CIA.S98102

32. Galbis-Estrada C, Pinazo-Durán MD, Martínez-Castillo S, Morales JM, Monleón D, Zanon-Moreno V. A metabolomic approach to dry eye disorders. The role of oral supplements with antioxidants and omega 3 fatty acids. Mol Vis. 2015;21:555-567.

33. Muscogiuri G, Barrea L, Savastano S, Colao A. Nutritional recommendations for CoVID-19 quarantine. Eur J Clin Nutr. 2020:1-2.

34. Moynihan AB, van Tilburg WA, Igou ER, Wisman A, Donnelly AE, Mulcaire JB. Eaten up by boredom: consuming food to escape awareness of the bored self. Front Psychol. 2015;6:369. doi:10.3389/fpsyg.2015.00369

35. Astrup A, Bügel S. Overfed but undernourished: recognizing nutritional inadequacies/deficiencies in patients with overweight or obesity. Int J Obes. 2019;43(2):219-232.

36. García OP, Long KZ, Rosado JL. Impact of micronutrient deficiencies on obesity. Nutr Rev. 2009;67:559-572. doi:10.1111/j.17534887.2009.00228.x

37. Mattioli AV, Sciomer S, Cocchi C, et al. Quarantine during COVID-19 outbreak: changes in diet and physical activity increase the risk of cardiovascular disease. Nutr Metab Cardiovasc Dis. 2020;30(9):1409-1417. doi:10.1016/j.numecd.2020.05.020
38. Walsh NP, Fortes MB, Raymond-Barker P, et al. Is whole-body hydration an important consideration in dry eye? Invest Ophthalmol Vis Sci. 2012;53(10):6622-6627. doi:10.1167/iovs.12-10175

39. Clay JM, Parker MO. Alcohol use and misuse during the COVID-19 pandemic: a potential public health crisis? Lancet Public Health. 2020;5(5):e259. doi:10.1016/S2468-2667(20)30088-8.

40. Coronavirus disease (COVID-19) outbreak [online information portal]. Copenhagen: WHO Regional Office for Europe; 2020. Available from: https://www.euro.who.int/en/health-topics/diseaseprevention/alcohol-use/data-and-statistics/fact-sheet-alcohol-andcovid-19-what-you-need-to-know-2020. Accessed September 21, 2020.

41. Coronavirus disease (COVID-19) outbreak [online information portal]. Copenhagen: WHO Regional Office for Europe; 2020. Available from: http://www.euro.who.int/en/health-topics/healthemergencies/coronavirus-covid-19. Accessed September 21, 2020.

42. Coronavirus disease (COVID-19) outbreak [online information portal]. Copenhagen: WHO Regional Office for Europe; 2020. Available from: https://www.euro.who.int/en/health-topics/diseaseprevention/alcohol-use/news/news/2020/04/alcohol-does-not-protectagainst-covid-19-access-should-be-restricted-during-lockdown. Accessed September 21, 2020.

43. Associated Press. Booze buying surges; senators push airlines for cash refunds; March 31, 2020. Available from: https://apnews.com/ c407ecb931c6c528b4cceb0ecc216f0c. Accessed September 21, 2020.

44. Vaillant GE. The Natural History of Alcoholism Revisited. Cambridge, Mass: Harvard University Press; 1995:xiii, 446.

45. Kim JH, Kim JH, Nam WH, et al. Oral alcohol administration disturbs tear film and ocular surface. Ophthalmology. 2012;119 (5):965-971. doi:10.1016/j.ophtha.2011.11.015

46. Peragallo J, Biousse V, Newman NJ. Ocular manifestations of drug and alcohol abuse. Curr Opin Ophthalmol. 2013;24(6):566-573. doi:10.1097/ICU.0b013e3283654db2

47. Cumurcu T, Gunduz A, Cumurcu BE, Gül IG, Akpolat N, Karlidag R. The changes in tear film parameters and impression cytology in heavily drinking men. Cornea. 2013;32(3):237-241. doi:10.1097/ICO.0b013e31825239d1

48. You YS, Qu NB, Yu XN. Alcohol consumption and dry eye syndrome: a meta-analysis. Int J Ophthalmol. 2016;9(10):1487-1492. doi:10.18240/ijo.2016.10.20

49. Ross A. Vitamin A and carotenoids. In: Shils M, Shike M, Ross A, Caballero B, Cousins R, editors. Modern Nutrition in Health and Disease. 10th ed. Baltimore, MD: Lippincott Williams \& Wilkins; 2006:351-375.

50. Abedi E, Sahari MA. Long-chain polyunsaturated fatty acid sources and evaluation of their nutritional and functional properties. Food $S \mathrm{Ci}$ Nutr. 2014;2(5):443-463. doi:10.1002/fsn3.121

51. Akhtar S, Ahmed A, Randhawa MA, et al. Prevalence of vitamin A deficiency in South Asia: causes, outcomes, and possible remedies. J Health Popul Nutr. 2013;31(4):413.

52. West KP, Darnton-Hill I. Vitamin A deficiency. In: Semba RD, Bloem M, eds. Nutrition and Health in Developing Countries. 2nd Ed. Totowa, NJ: Humana Press; 2008:377-433.

53. Alpalhão $\mathrm{M}$, Filipe $\mathrm{P}$. SARS-CoV-2 pandemic and Vitamin D deficiency-a double trouble. Photodermatol Photoimmunol Photomed. 2020;36(5):412-413. doi:10.1111/phpp.12579

54. Trovas G, Tournis S. Vitamin D and COVID-19. Hormones. 2020;14:1-2.

55. Tocher DR, Betancor MB, Sprague M, Olsen RE, Napier JA. Omega3 long-chain polyunsaturated fatty acids, EPA and DHA: bridging the gap between supply and demand. Nutrients. 2019;11(1):89. doi:10.3390/nu11010089

56. Szakáts I, Sebestyén M, Németh J, Birkás E, Purebl G. The role of health anxiety and depressive symptoms in dry eye disease. Curr Eye Res. 2016;41:1044-1049. doi:10.3109/02713683.2015.108 8955 
57. Han SB, Yang HK, Hyon JY, Wee WR. Association of dry eye disease with psychiatric or neurological disorders in elderly patients. Clin Interv Aging. 2017;12:785-792. doi:10.2147/CIA. $\mathrm{S} 137580$

58. Ettman CK, Abdalla SM, Cohen GH, Sampson L, Vivier PM, Galea S. Prevalence of depression symptoms in US adults before and during the COVID-19 pandemic. JAMA Network Open. 2020;3 (9):e2019686. doi:10.1001/jamanetworkopen.2020.19686

59. Czeisler MÉ, Lane RI, Petrosky E, et al. Mental health, substance use, and suicidal ideation during the COVID-19 pandemic - United States, June 24-30, 2020. MMWR Morb Mortal Wkly Rep. 2020;69 (32):1049. doi:10.15585/mmwr.mm6932a1

60. Acan D, Kurtgoz P. Influence of selective serotonin reuptake inhibitors on ocular surface. Clin Exp Optom. 2017;100:83-86. doi:10.1111/cxo.12415

61. Narayanan V. Ocular Adverse effects of antidepressants - need for an ophthalmic screening and follow up protocol. Ophthalmol Res. 2019;10(3):1-6. doi:10.9734/or/2019/v10i330107

62. Morin CM, Carrier J. The acute effects of the COVID-19 pandemic on insomnia and psychological symptoms. Sleep Med. 2020. doi:10.1016/j.sleep.2020.06.005

63. Lin LY, Wang J, Ou-yang XY, et al. The immediate impact of the 2019 novel coronavirus (COVID-19) outbreak on subjective sleep status. Sleep Med. 2020. doi:10.1016/j.sleep.2020.05.018

64. Cellini N, Canale N, Mioni G, Costa S. Changes in sleep pattern, sense of time and digital media use during COVID-19 lockdown in Italy. J Sleep Res. 2020:e13074.

65. Sinha M, Pande B, Sinha R. Impact of COVID-19 lockdown on sleep-wake schedule and associated lifestyle related behavior: a national survey. J Public Health Res. 2020;9(3). doi:10.4081/ jphr.2020.1826

66. Zhang C, Yang L, Liu S, et al. Survey of insomnia and related social psychological factors among medical staff involved in the 2019 novel coronavirus disease outbreak. Front Psychiatry. 2020;11:306. doi:10.3389/fpsyt.2020.00306

67. Zhou SJ, Wang LL, Yang R, et al. Sleep problems among Chinese adolescents and young adults during the coronavirus-2019 pandemic. Sleep Med. 2020;74:39-47. doi:10.1016/j.sleep.2020.06.001

68. Altena E, Baglioni C, Espie CA, et al. Dealing with sleep problems during home confinement due to the COVID-19 outbreak: practical recommendations from a task force of the European CBT-I Academy. J Sleep Res. 2020:e13052.

69. Li S, Ning K, Zhou J, et al. Sleep deprivation disrupts the lacrimal system and induces dry eye disease. Exp Mol Med. 2018;50:e451. doi:10.1038/emm.2017.285
70. Wu M, Liu X, Han J, Shao T, Wang Y. Association between sleep quality, mood status, and ocular surface characteristics in patients with dry eye disease. Cornea. 2019;38:311-317. doi:10.1097/ ICO.0000000000001854

71. Kostev K, Lauterbach S. Panic buying or good adherence? Increased pharmacy purchases of drugs from wholesalers in the last week prior to Covid-19 lockdown. $J$ Psychiatr Res. 2020;130:19-21. doi:10.1016/j.jpsychires.2020.07.005

72. Hao F, Tan W, Jiang L, et al. Do psychiatric patients experience more psychiatric symptoms during COVID-19 pandemic and lockdown? A case-control study with service and research implications for immunopsychiatry. Brain Behav Immun. 2020;87:100-106. doi:10.1016/j.bbi.2020.04.069

73. BBC Coronavirus: why some people with symptoms in India are living in trees; 2020. Available from: https://www.bbc.com/news/av/ world-asia-52129158/coronavirus-why-some-people-with-symptomsin-india-are-living-in-trees. Accessed September 21, 2020.

74. Napoli PE, Mangoni L, Gentile P, Braghiroli M, Fossarello M. A panel of broad-spectrum antivirals in topical ophthalmic medications from the drug repurposing approach during and after the coronavirus disease 2019 era. J Clin Med. 2020;9:2441. doi:10.3390/ jcm9082441

75. Tosini G, Ferguson I, Tsubota K. Effects of blue light on the circadian system and eye physiology. Mol Vis. 2016;22:61.

76. Van Der Meijden WP, Van Someren JL, Te Lindert BH, et al. Individual differences in sleep timing relate to melanopsin-based phototransduction in healthy adolescents and young adults. Sleep. 2016;39(6):1305-1310. doi:10.5665/sleep.5858

77. Kimberly B, James RP. Amber lenses to block blue light and improve sleep: a randomized trial. Chronobiol Int. 2009;26(8):1602-1612. doi:10.3109/07420520903523719

78. American Academy of Ophthalmology. Computers, digital devices and eye strain; March 18, 2020. Available from: https://www.aao.org/ eye-health/tips-prevention/computer-usage. Accessed September 21, 2020.

79. American Academy of Ophthalmology. Eye strain: how to prevent tired eyes; February 26, 2020. Available from: https://www.aao.org/ eye-health/diseases/what-is-eye-strain. Accessed September 21, 2020.

80. American Academy of Ophthalmology. Is too much screen time harming children's vision?; August 06, 2020. Available from: https://www.aao.org/newsroom/news-releases/detail/is-too-muchscreen-time-harming-childrens-vision. Accessed September 21, 2020.
Risk Management and Healthcare Policy

\section{Publish your work in this journal}

Risk Management and Healthcare Policy is an international, peerreviewed, open access journal focusing on all aspects of public health, policy, and preventative measures to promote good health and improve morbidity and mortality in the population. The journal welcomes submitted papers covering original research, basic science, clinical \& epidemiological studies, reviews and evaluations, guidelines, expert opinion and commentary, case reports and extended reports. The manuscript management system is completely online and includes a very quick and fair peer-review system, which is all easy to use. Visit http://www.dovepress.com/testimonials.php to read real quotes from published authors. 